\title{
A Self-Determination Theory Perspective on Postpartum Depressive Symptoms and Early Parenting Behaviors
}

Article in Journal of Clinical Psychology · April 2017

DOI: $10.1002 / j \mathrm{jl} .22480$

CITATIONS

4

\section{2 authors:}

A Katrijn Brenning

Ghent University

31 PUBLICATIONS 336 CITATIONS

SEE PROFILE

\section{READS}

199

Bart Soenens

Ghent University

232 PUBLICATIONS 11,986 CITATIONS

SEE PROFILE

Some of the authors of this publication are also working on these related projects:

Illuminating Bright and Dark Sides of Parenting a Child With Down Syndrome, Cerebral Palsy or Autism Spectrum Disorder: Evaluating Need-satisfaction and -Frustration as Keys to Well- and Ill-being in Parents and Their Children. View project 


\title{
A Self-Determination Theory Perspective on Postpartum Depressive Symptoms and Early Parenting Behaviors
}

\author{
Katrijn Brenning and Bart Soenens
}

\author{
Ghent University
}

Objective: On the basis of self-determination theory, this study investigates longitudinal associations between satisfaction and frustration mothers' basic psychological needs (i.e., autonomy, relatedness, competence) and mothers' postnatal depressive symptoms and early parenting behaviors. Method: Participants were 214 women assessed during their pregnancy (Time 1), 4 months after delivery (Time 2), and when the child was 2 years old (Time 3). Results: Results demonstrate effects of prenatal basic psychological needs (needs frustration more specifically) on postnatal depressive symptoms. In addition, general prenatal needs satisfaction and frustration predicted more relationship-specific needs satisfaction and frustration, respectively (in the mother-child relationship). In turn, postnatal relationship-specific needs satisfaction predicted more high-quality parenting when the child is 2 years old. More specifically, needs satisfaction was related to more maternal responsiveness and autonomy support. Conclusion: Overall, these findings underscore the importance of psychological needs experiences for both mothers' personal adjustment after birth and for the early mother-child relationship. (C) 2017 Wiley Periodicals, Inc. J. Clin. Psychol. 00:1-15, 2017.

Keywords: early parenting; postpartum depressive symptoms; self-determination theory

The birth of a child is an important, identity-defining, but also potentially challenging life transition (Cowan \& Cowan, 2000). Many women experience the transition to parenthood as an exciting and thrilling period. However, at least for some women, the transition to parenthood goes along with lowered psychosocial well-being (Gavin et al., 2005). Postpartum depression is the most common psychological complication of childbirth, affecting between $10 \%$ and $15 \%$ of mothers (Miller, 2002). However, a much larger percentage of women (between 15\% and 30\%) report nonclinical levels of depressive symptoms after childbirth, which can be referred to as postpartum depressive symptoms (Goodman, 2004).

The transition to parenthood forms a challenge at not only the intra-individual level (potentially increasing the risk of postnatal depressive symptoms) but also the interpersonal level (Gavin et al., 2005). For instance, the transition to parenthood involves a renegotiation of the partner relationship, with the birth of the child affecting many features of a partner relationship (e.g., amount of time spent together). At the interpersonal level, mothers also develop a particular style of interacting with the child, with early parenting style affecting the quality of the mother-child relationship (Bowlby, 1980) and many features of the child's development (Kochanska, Aksan, Knaack, \& Rhines, 2004; Kochanska, Murray, \& Harlan, 2000).

Much research has been done to identify risk factors for postnatal depressive symptoms (Beck, 1996, 2001) and an increasing number of studies examines antecedents of mothers' early

We have no conflict of interest to declare.

This work was supported by the Research Foundation - Flanders (grant number FWO.3EO.2015.0012.01).

Please address correspondence to: K. M. Brenning, Ghent University, Department of Developmental, Personality and Social Psychology, Henri Dunantlaan 2, 9000 Ghent, Belgium. E-mail: Katrijn.Brenning@Ugent.be 
parenting (e.g., Verhoeven, Junger, Van Aken, Dekovic, \& Van Aken, 2007). Fewer studies, however, have attempted to unravel psychological processes involved in both important domains of mothers' postnatal functioning simultaneously. An examination of such processes requires a theory postulating psychological processes with relevance to both intrapersonal and interpersonal adjustment. One such theory is self-determination theory (SDT; Deci \& Ryan, 2000; Vansteenkiste, Niemiec, \& Soenens, 2010), which identifies three basic psychological needs as universal and essential ingredients for healthy psychological and social development. These basic psychological needs are the needs for autonomy (which involves the experience of a sense of volition and self-endorsement in one's activities), competence (which refers to the experience of effectiveness when interacting with one's environment), and relatedness (which involves the experience of reciprocal care and concern for each other).

In line with SDT, empirical research has shown that psychological needs satisfaction is related to indicators of both interpersonal and intrapersonal well-being, whereas frustration is related to more psychosocial problems (e.g., Bartholomew, Ntoumanis, Ryan, Bosch, \& ThogersenNtoumani, 2011; Patrick, Knee, Canevello, \& Lonsbary, 2007). Although the relevance of the three basic psychological needs for psychosocial adjustment has been shown in abundant studies in middle childhood, adolescence, and adulthood (Ryan \& Deci, 2000), research during the transition to parenthood is scarce. The overall aim of the current study is to examine the predictive role of prenatal maternal needs satisfaction and frustration for mothers' own depressive symptoms after childbirth as well as quality of early parenting style toward the child.

\section{Basic Psychological Needs and Depressive Symptoms}

According to SDT (Deci \& Ryan, 2000; Vansteenkiste et al., 2010), a lack of needs satisfaction or the presence of needs frustration may form a risk for psychopathology (including depressive symptoms). Several studies already provided evidence for this link (in children, adolescents, and adults; for a review study, see Ryan, Deci, \& Vansteenkiste, 2016). However, only two studies to date investigated the role of basic psychological needs in maternal well-being during (early) parenthood. Brenning, Soenens, and Vansteenkiste (2015) reported evidence for the importance of prenatal basic psychological needs in mothers' prenatal depressive symptoms, while Gauthier, Guay, Senecal, and Pierce (2010) reported evidence for a similar association with postnatal depressive symptoms. The study by Brenning et al. (2015) is cross-sectional in nature, whereas the study by Gauthier et al. (2010) is the only study investigating the dynamics longitudinally. Specifically, this study found reciprocal effects between anxious attachment (conceptually related to relatedness) and postpartum depressive symptoms, and found that high levels of parental autonomous motivation (autonomy) predict lower levels of depressive symptoms. Because the study by Gauthier et al. (2010) did not use a direct measure to tap into the SDT-based constructs of the needs, the present study aims to contribute to this limited body of research by using a specific measure directly tapping into basic psychological needs fulfillment.

Further, the present study distinguishes between needs satisfaction and needs frustration, a distinction that increasingly receives attention in recent SDT-based research. Recent theorizing and research suggest that the frustration of the psychological needs cannot be equated with a lack of needs satisfaction (Bartholomew et al., 2011; Vansteenkiste \& Ryan, 2013). When a mother has few opportunities to learn new and challenging skills (low competence needs satisfaction), this does not necessarily mean that she felt like a failure (competence needs frustration). Because frustration involves a stronger threat to individuals' needs than a lack of satisfaction, needs frustration is said to be particularly relevant to ill-being and maladjustment (rather than just an absence of well-being). Research indeed has begun to show that needs satisfaction is particularly predictive of well-being and adaptive outcomes and that needs frustration is particularly predictive of ill-being and risk for psychopathology (Bartholomew et al., 2011; Ryan et al., 2016).

As such, the first aim of the present study was to test the link between prenatal maternal basic psychological needs satisfaction and frustration and postnatal depressive symptoms. Because 
previous research showed that postpartum depressive symptoms form a risk factor for depressive symptoms later on (e.g., Woolhouse, Gartland, Mensah, Giallo, \& Brown, 2016), the current study also incorporates maternal depressive symptoms when the child is 2 years old. If the present study indeed supports this continuity between postpartum depressive symptoms and maternal depressive symptoms when the child is 2 years old, then it becomes even more important to look into the antecedents of postpartum depressive symptoms and investigate whether maternal prenatal psychological needs play a role. Further, the current study aims to test whether prenatal maternal needs satisfaction and frustration would be related to postnatal needs experiences in the mother-child relationship and whether these relationship-specific psychological needs would be related to quality of parenting when the child is 2 years old.

\section{Relationship-Specific Basic Psychological Needs and Quality of Parenting}

Next to the importance of investigating general feelings of needs satisfaction and frustration, SDT points to the importance of investigating the role of needs fulfillment in specific life domains (e.g., school, work, relationships, leisure) and relationships (Deci \& Ryan, 2008; Milyavskaya \& Koestner, 2011; Patrick et al., 2007). Based on previous research, general needs satisfaction and frustration (i.e., general level) is expected to influence domain-specific and relationshipspecific needs experiences (i.e., contextual level), which in turn may translate in specific behaviors (Milyavskaya, Philippe, \& Koestner, 2013). The present study aims to add to this body of research by investigating whether mothers' general prenatal basic psychological needs satisfaction and frustration would relate to their postnatal needs experiences in the mother-child relationships (i.e., relationship specific).

Further, the present study aims to investigate the link between these relationship-specific basic psychological needs (i.e., needs satisfaction and frustration in the mother-child relationship) and maternal parenting behaviors (as measured when the child is 2 years old). Does maternal psychological needs satisfaction present a critical resource for mothers for providing high-quality parenting, whereas needs frustration presents a parental risk factor for providing low-quality parenting? Based on SDT, it is expected that mothers' own satisfaction and frustration of their basic psychological needs are indeed related to their parenting behaviors (e.g., Mabbe, Soenens, Vansteenkiste, van der Kaap-Deeder, \& Mouratidis, in press; van der KaapDeeder et al., 2015). Specifically, when parents experience a sense of psychological freedom and volition in interaction with their child (i.e., autonomy satisfaction), feel competent as a parent (i.e., competence satisfaction), and feel related to their child (i.e., relatedness satisfaction), they would generate a level of energy, attentiveness, patience, and open-mindedness required to provide high-quality parenting (Joussemet, Landry, \& Koestner, 2008; Ryan \& Frederick, 1997).

Quality of parenting is conceptualized in this study in terms of two parenting dimensions that have been shown to be essential for young children's healthy development and that are central to SDT, namely, responsiveness and autonomy support (see, e.g., Bernier, Matte-Gagne, Belanger, \& Whipple, 2014; Bindman, Pomerantz, \& Roisman, 2015; Whipple, Bernier, \& Mageau, 2011). Responsiveness refers to the parent's capacity to interact with children in a warm, affectionate, and involved fashion (Davidov \& Grusec, 2006) and provide security when a child experiences discomfort or stress (Soenens, Duriez, Vansteenkiste, \& Goossens, 2007).

Autonomy support refers to the parents' capacity to encourage their children to behave on the basis of self-endorsed motives and preferences (Grolnick, Deci, \& Ryan, 1997; Soenens, Vansteenkiste, et al., 2007). Specifically, autonomy-supportive parents try to know and understand the perspective of their children (i.e., empathy); they avoid the use of pressuring tactics to regulate the behavior of their children; and they provide choices whenever possible (Ryan, Deci, Grolnick, \& La Guardia, 2006). Although previous studies already showed a link between parents' basic psychological needs and autonomy-supportive parenting behaviors (e.g., van der Kaap-Deeder et al., 2015), no study to date investigated this link longitudinally in mothers and their toddlers. In addition, the present study also investigates for the first time the link between basic psychological needs fulfillment and responsiveness. 


\section{The Present Study}

The objective of the present longitudinal study was to explore the associations between mothers' basic psychological needs, depressive symptoms, and quality of parenting. Three more specific aims were pursued. First, we aimed to investigate the link between prenatal psychological needs (satisfaction and frustration) and postnatal depressive symptoms. In turn, postnatal depressive symptoms were expected to predict maternal depressive symptoms 2 years later. Second, we aim to examine associations between prenatal general needs satisfaction and frustration and postnatal relationship-specific needs fulfillment. And third, we aim to investigate the link between postnatal relationship-specific needs fulfillment and quality of parenting behaviors when the child is 2 years old.

\section{Method}

\section{Participants}

The sample was taken from a larger longitudinal project on maternal well-being during the transition to motherhood, using data from Wave 1 (prenatal), Wave 2 (4 months postnatal), and Wave 3 (approximately 2 years postnatal). Initially 214 mothers participated in this study during their second or third trimester of pregnancy (Wave 1; Brenning, Soenens \& Vansteenkiste, 2015). At Wave 2, 136 mothers participated again in the study shortly after childbirth (Wave 2; Brenning, Soenens, Mabbe \& Vansteenkiste, 2017). Eight mothers did not wish to participate, 19 mothers could not participate because they did not rely on daycare (which was an inclusion criteria for Wave 2, due to the larger project's research aim), and 51 mothers were not attainable at Wave 2 (e.g., no contact information available, $N=34$ ). At Wave 3, 157 mothers participated when their child was 1.5 to 2.5 years old; 19 mothers did not wish to participate and 38 mothers were not attainable at Wave 3 . Wave 3 data were gathered in the context of a course on developmental psychology. Undergraduate students contacted all participating mothers and visited the participants at home, to hand them a set of paper-and-pencil questionnaires. Participation in the study was voluntary and confidentiality was guaranteed. Informed consent was obtained from all participants in the study. The organizing university's institutional review board granted ethical approval for this study.

Of the 214 mothers participating at Time 1, $114(53.27 \%)$ participated at all measurement times; $65(30.37 \%)$ participated two times $(N=22$ at Time 1 and Time $2 ; N=43$ at Time 1 and Time 3); and $35(16.36 \%)$ participated only at Time 1 . Little's missing completely at random test produced a $\chi^{2}(101)$ of $110.11(p>.05)$, which indicates that the data were likely to be missing at random and that it is safe to include cases with missing values in the analyses. Cases with missing values were included in the analyses using full-information maximum likelihood estimation (Little \& Rubin, 1987).

The initial sample (Time $1, N=214$, mean age $=28.31$, range 18-41) included 150 primiparous women $(70.1 \%)$. The other women were expecting their second $(n=45)$, third $(n=13)$, fourth $(\mathrm{n}=5)$, or fifth $(\mathrm{n}=1)$ baby. Of the women, 203 were married or lived together with their partner $(96.2 \%)$, two women were divorced, one woman was divorced but lived together with a new partner (who is not the biological father of the baby) in a reconstituted family, and five women were conscious single mothers. Regarding type of pregnancy, 189 mothers got pregnant in a natural way $(88.7 \%)$, whereas others needed medical assistance.

\section{Measures}

Depressive symptoms. At all measurement waves (Time 1, Time 2, Time 3), women's depressive symptoms were measured with the Center for Epidemiologic Studies-Depression Scale (CES-D; Radloff, 1977). The 12-item CES-D is a brief version of the original 20-item CESD, which was developed by Roberts and Sobhan (1992), who found a correlation of 96 between the brief and the full version of the CES-D. Research with the Dutch translation of the CES-D has demonstrated good reliability and validity for both the 20-item CES-D (Bouma, Ranchor, Sanderman, \& van Sonderen, 1995) and the 12-item CES-D (Soenens, Luyckx, Vansteenkiste, 
Duriez, \& Goossens, 2008). In this study, we used the 12 -item version. Using this questionnaire, mothers rated how often they experienced cognitive, somatic, and psychological symptoms of depression during the past week (e.g., feeling sad) on a scale ranging from 0 (rarely or none of the times) to 3 (most or all of the time). For each individual, a total depressive symptoms score was calculated by taking the mean of the responses. Cronbach's alphas were $.83, .85$, and .83 at Time 1, Time 2, and Time 3, respectively.

Prenatal general basic psychological needs. To capture satisfaction and frustration of women's basic psychological needs, we administered the Basic Psychological Needs Scale (BPNS; Chen et al., 2015). At Time 1, all mothers filled out the full 24-item version, with 12 items tapping into needs satisfaction (e.g., for autonomy satisfaction, "I feel a sense of choice and freedom in the things I undertake"), and 12 items tapping into the needs frustration (e.g., for competence frustration, "I have serious doubts about whether I can do things well"). All items were rated on a 5-point scale ranging from 1 (strongly disagree) to 5 (strongly agree). Each 12-item scale has four items tapping into autonomy, four items tapping into competence, and four items tapping into relatedness. For each individual, total needs satisfaction and total needs frustration scores were calculated by taking the means of the 12 needs satisfaction scores and the 12 needs frustration scores, respectively. Chen et al. (2015) provided evidence for the psychometric properties of the BPNS. In the current study, Cronbach's alphas were .80 for needs satisfaction and .85 for needs frustration.

Postnatal relationship-specific basic psychological needs. At Time 2, using a 5-day diary format, mothers filled out a shortened version of the BPNS (i.e., 12 of 24 items). These items were slightly adapted to make them amenable to the diary assessment (which may limit retrospective bias) and focus specifically on the mother-child interactions (see Mabbe et al., in press). Satisfaction and frustration of each of the three needs were measured with two items: autonomy satisfaction (e.g., "Today, I felt a sense of choice and freedom in the things I did with my child") and frustration (e.g., "Today, I felt forced to do things for my child I didn't choose to do"); competence satisfaction (e.g., "Today, I felt confident in what I did for my child") and frustration (e.g., "Today, I felt insecure about my abilities with my child"); and relatedness satisfaction (e.g., "Today, I felt connected with my child") and frustration (e.g., "Today, I felt a distance between my baby and me"). Items were rated on a scale ranging from 1 (completely not true) to 5 (completely true). For each day, total needs satisfaction and total needs frustration scores were calculated by taking the means of the six needs satisfaction scores and the six needs frustration scores, respectively. Then, for each individual, the aggregate scores from the five consecutive days (by taking the mean of the scores that were obtained day by day) were used. Cronbach's alphas were .72 for needs satisfaction and .70 for needs frustration.

Parental responsiveness. At Time 3, maternal responsiveness was measured with the seven-item version of the acceptance/rejection subscale from the revised Child Report on Parenting Behavior Inventory (Schaefer, 1965). The parent-report version of this child-report questionnaire has been used as valid and reliable measures of responsiveness in past research (Brenning, Soenens, Braet, \& Bal, 2012; Soenens, Vansteenkiste, Luyckx, \& Goossens, 2006). A sample item reads: "I am able to make my child feel better when my child is upset." All items were scored on a scale ranging from 1 (not at all) to 5 (very much). A total responsiveness score was calculated by taking the mean of all item scores. In this study, Cronbach's alpha was .78.

Autonomy support. To assess autonomy-supportive parenting, we administered the sevenitem Autonomy Support subscale of the Perceptions of Parents Scale (Grolnick, Ryan, \& Deci, 1991). The parent-report version of this questionnaire has been used as a valid and reliable measure in previous research (Brenning et al., 2012; Soenens et al., 2006). A sample item reads: "Whenever possible, I allow my child to choose what to do." All items are scored on a scale ranging from 1 (not at all) to 5 (very much). A total autonomy support score was calculated by taking the mean of all item scores. Cronbach's alpha of this scale was .69. 


\section{Results}

\section{Descriptive Statistics and Preliminary Analyses}

Correlations among the study variables are presented in Table 1. As expected, prenatal basic psychological needs satisfaction correlated negatively with postpartum depressive symptoms $(r=$ $-.30, p<.001)$, whereas prenatal basic psychological needs frustration correlated positively with postnatal depressive symptoms $(r=.40, p<.001)$. Further, general prenatal basic psychological needs satisfaction and frustration correlated positively with postnatal relationship-specific needs satisfaction $(r=.30, p<.01)$ and frustration $(r=.54, p<.001)$, respectively. Regarding the link with parenting quality (Time 3 ), both domain-specific needs (needs satisfaction more specifically) and postpartum depressive symptoms correlated significantly with parenting quality. Specifically, postnatal basic psychological needs satisfaction correlated positively with responsiveness $(r=.30, p<.01)$ and autonomy support $(r=.50, p<.001)$. Regarding postnatal depressive symptoms, a significantly negative relationship was found with autonomy support $(r=-.23$, $p<.05)$, although the link with responsiveness was non-significant $(r=-.14, p>.05)$. Table 1 also presents the means and standard deviations of all study variables.

Next, preliminary analyses were conducted to examine differences in the study variables in terms of mother's age, number of children, family structure and type of pregnancy. A first multivariate analysis of covariance (MANCOVA) examined the effects on basic psychological needs satisfaction and frustration as measured at Time 1 (general measurement) and Time 2 (relationship-specific measurement). No significant multivariate effects were obtained for mother's age, Wilk's Lambda $=.93, F(4,87)=1.66, p>.05$; number of children, Wilk's Lambda $=.97, F(4,87)=0.70, p>.05$; family structure, Wilk's Lambda $=.96, F(4,87)=0.81$, $p>.05$; and type of pregnancy, Wilk's Lambda $=.97, F(4,87)=0.74, p>.05$.

Table 1

Means, Standard Deviations, and Correlations Among the Measured Variables

\begin{tabular}{|c|c|c|c|c|c|c|c|c|c|}
\hline & 1 & 2 & 3 & 4 & 5 & 6 & 7 & 8 & 9 \\
\hline \multicolumn{10}{|l|}{$\begin{array}{l}\text { 1. Prenatal need } \\
\text { satisfaction }\end{array}$} \\
\hline $\begin{array}{l}\text { 2. Prenatal need } \\
\text { frustration }\end{array}$ & $-.58^{* * *}$ & & & & & & & & \\
\hline $\begin{array}{l}\text { 3. Postnatal need } \\
\text { satisfaction }\end{array}$ & $.30^{* *}$ & $-.27^{* *}$ & & & & & & & \\
\hline $\begin{array}{l}\text { 4. Postnatal need } \\
\text { frustration }\end{array}$ & $-.22^{*}$ & $.54^{* * *}$ & $-.59^{* * *}$ & & & & & & \\
\hline $\begin{array}{l}\text { 5. Prenatal } \\
\text { depressive } \\
\text { symptoms }\end{array}$ & $-.36^{* * *}$ & $.46^{* * *}$ & $-.39^{* * *}$ & $.32^{* *}$ & & & & & \\
\hline $\begin{array}{l}\text { 6. Postnatal } \\
\text { depressive } \\
\text { symptoms }\end{array}$ & $-.30^{* * *}$ & $.40^{* * *}$ & $-.38^{* * *}$ & $.42^{* * *}$ & $.44^{* * *}$ & & & & \\
\hline $\begin{array}{l}\text { 7. Depressive } \\
\text { symptoms } 2 \text { years } \\
\text { postnatal }\end{array}$ & $-.30^{* * *}$ & $.38^{* * *}$ & $-.27^{*}$ & $.24^{*}$ & $.41^{* * * *}$ & $.44^{* * *}$ & & & \\
\hline $\begin{array}{l}\text { 8. Responsiveness } 2 \\
\text { years postnatal }\end{array}$ & $.30^{* * *}$ & $-.15^{\dagger}$ & $.30^{* *}$ & -.10 & -.11 & -.14 & -.13 & & \\
\hline $\begin{array}{l}\text { 9. Autonomy } \\
\text { support } 2 \text { years } \\
\text { postnatal }\end{array}$ & $.20^{*}$ & $-.13^{\dagger}$ & $.50^{* * *}$ & -.13 & $-.19^{*}$ & $-.23^{*}$ & $-.19^{*}$ & $.46^{* * *}$ & \\
\hline $\mathrm{M}$ & 4.08 & 1.82 & 4.23 & 1.37 & 0.73 & 0.59 & 0.54 & 4.69 & 4.10 \\
\hline SD & .42 & .50 & .45 & .41 & .44 & .45 & .41 & .33 & .46 \\
\hline
\end{tabular}

Note. $\mathrm{M}=$ mean; $\mathrm{SD}=$ standard deviation.

${ }^{\dagger} p<.10 .{ }^{*} p<.05 .{ }^{* *} p<.01 . * * * p<.001$. 
A second MANCOVA examined the effects on maternal depressive symptoms as measured at Time 1, Time 2, and Time 3. Again, no significant multivariate effects were obtained for mother's age, Wilk's Lambda $=.99, F(3,100)=0.50, p>.05$; number of children, Wilk's Lambda $=.99$, $F(3,100)=0.21, p>.05$; family structure, Wilk's Lambda $=.94, F(3,100)=2.17, p>.05$; and type of pregnancy, Wilk's Lambda $=1.00, F(3,100)=0.08, p>.05$.

Finally, a third MANCOVA examined the effects on parenting behaviors as measured at Time 3 (responsiveness and autonomy support). No significant multivariate effects were obtained for mother's age, Wilk's Lambda $=1.00, F(2,149)=0.38, p>.05$; family structure, Wilk's Lambda $=1.00, F(2,149)=0.19, p>.05$; and type of pregnancy, Wilk's Lambda $=.99$, $F(2,149)=0.70, p>.05$; a significant effect was found for number of children, Wilk's Lambda $=.96, F(2,149)=3.16, p<.05$, with mothers who have more children reporting less autonomy support $(r=-.23, p<.01)$. We controlled for this effect in all subsequent analyses.

\section{Primary Analyses}

To examine our research hypotheses we used structural equation modeling using MPlus (version 7.4; Muthén \& Muthén, 2012). For each construct, three to five randomly created parcels were computed. We evaluated model fit based on a combined consideration of the chi-square statistic $\left(\chi^{2}\right)$, the comparative fit index (CFI), the root mean square error of approximation (RMSEA), and the standardized root mean square residual (SRMR). The $\chi^{2}$ should be as small as possible. A CFI value of .90 or higher indicates a reasonable fit, whereas an RMSEA value of .06 or lower and a SRMR value of .08 or lower indicate acceptable fit (Kline, 2010). First, a confirmatory factor analysis was used to test the quality of the measurement model of the study constructs.

Second, a series of structural models was tested. Thereby, the role of basic psychological needs satisfaction and frustration was first tested in two separate encompassing models (one model regarding needs satisfaction, one regarding needs frustration), whereas a third more parsimonious integrated structural model examined the role of both needs satisfaction and frustration simultaneously.

Measurement model. The baseline model included nine latent variables (i.e., depressive symptoms at three measurement points; basic psychological needs satisfaction and frustration at two measurement points; parental responsiveness and autonomy support as measured at one measurement point) and 31 indicators (i.e., three to five parcels for each latent construct). The measurement errors of the same indicators at different measurement points were allowed to covary. This model fitted the data adequately, $\chi^{2}(381)=544.06, \mathrm{CFI}=.92, \mathrm{RMSEA}=$ .05 , SRMR $=.08$. Next, a model was estimated in which the factor loadings of depressive symptoms were set equal across the three measurement points. Compared to the model with freely varying factor loadings the latter model did not result in a significant loss in model fit, $\Delta \chi^{2}(4)=3.94, p>.05$. Moreover, all factor loadings were highly significant $(p<.001)$, ranging from .32 to .91 (mean $=.73$ ). In sum, evidence was obtained for a reliable and longitudinally invariant measurement model, which was used in all subsequent tests of the structural models.

Structural equation modeling. In a first structural model (Model 1, see Figure 1), we examined the associations between maternal basic psychological needs satisfaction, depressive symptoms, and quality of parenting. Estimation of Model $1, \chi^{2}(232)=286,77, \mathrm{CFI}=.96$, RMSEA $=.03$, SRMR $=.07$, showed no significant effect of prenatal basic psychological needs satisfaction on postnatal depressive symptoms. However, prenatal psychological needs satisfaction was significantly related to postnatal relationship-specific needs satisfaction ( $\beta=$ $.40, p<.01)$. Finally, psychological needs satisfaction in relation to the child was significantly related to both maternal responsiveness $(\beta=.42, p<.05)$ and maternal autonomy support $(\beta=.64, p<.001)$.

In a second structural model (Model 2, see Figure 2), we examined the associations between maternal basic psychological needs frustration, depressive symptoms, and quality of parenting. 
A SELF-DETERMINATION THEORY PERSPECTIVE

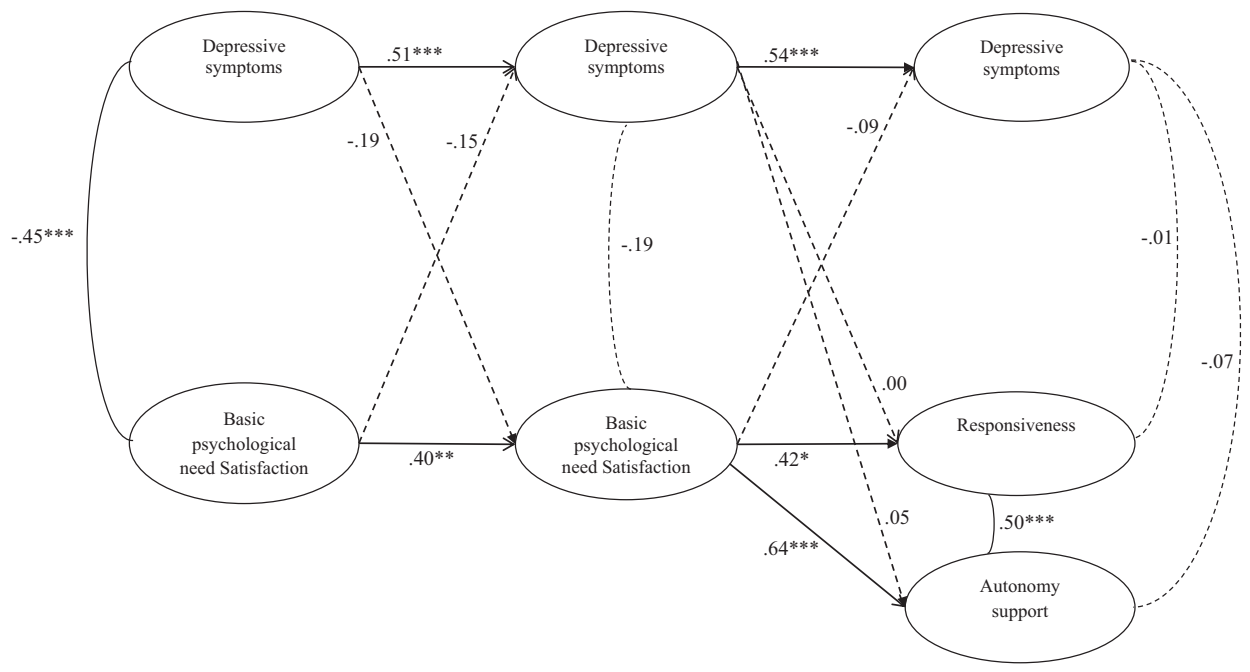

Figure 1. Model need satisfaction. Coefficients shown are standardized path coefficients, ${ }^{*} \mathrm{p}<.05 .{ }^{* *} \mathrm{p}<$ $.01 . * * * \mathrm{p}<.001$.

A SELF-DETERMINATION THEORY PERSPECTIVE

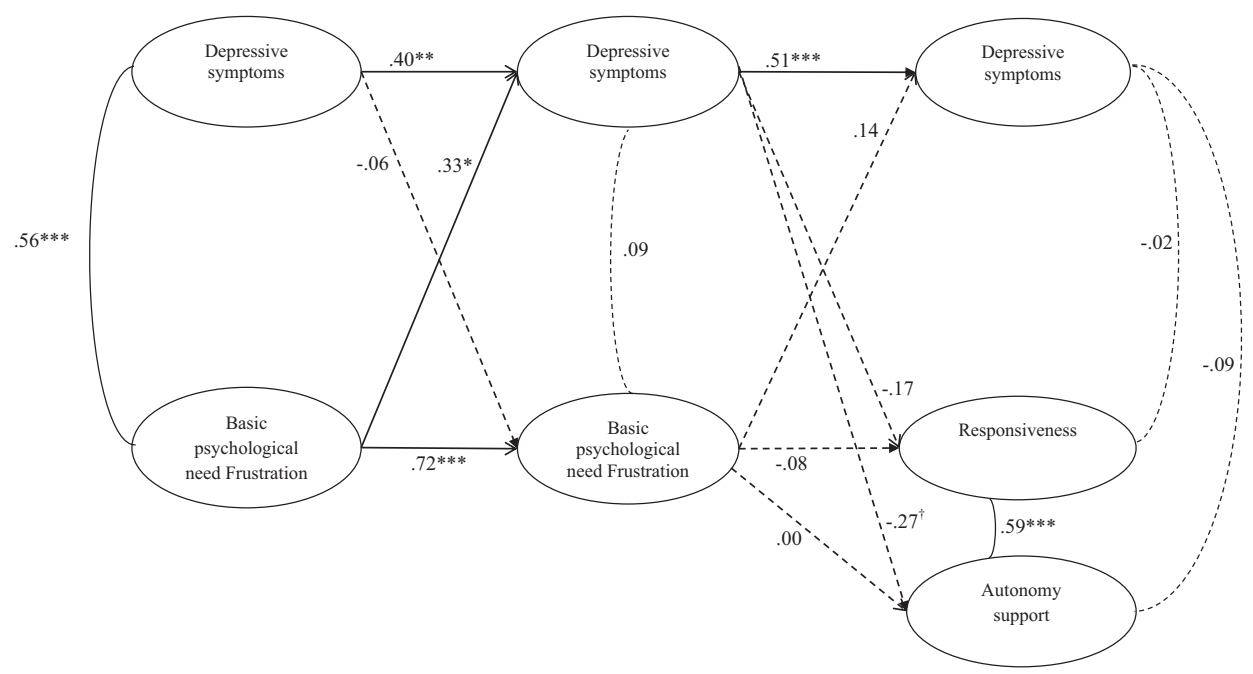

Figure 2. Model need frustration. Coefficients shown are standardized path coefficients, $\uparrow \mathrm{p}<.10,{ }^{*} \mathrm{p}<$ $.05 . * * \mathrm{p}<.01 . * * * \mathrm{p}<.001$.

Estimation of Model 2, $\chi^{2}(232)=332,89, \mathrm{CFI}=.93, \mathrm{RMSEA}=.05$, SRMR $=.08$, showed a significant effect of prenatal basic psychological needs frustration on increases in depressive symptoms from the prenatal to the postnatal assessment $(\beta=.33, p<.05)$.In turn, postpartum depressive symptoms were significantly related to depressive symptoms 2 years later $(\beta=.51$, $p<.001)$. Further, prenatal psychological needs frustration was significantly related to postnatal relationship-specific needs frustration $(\beta=.72, p<.001)$. No significant associations were found between relationship-specific needs frustration and parental responsiveness or autonomy support. 
A SELF-DETERMINATION THEORY PERSPECTIVE

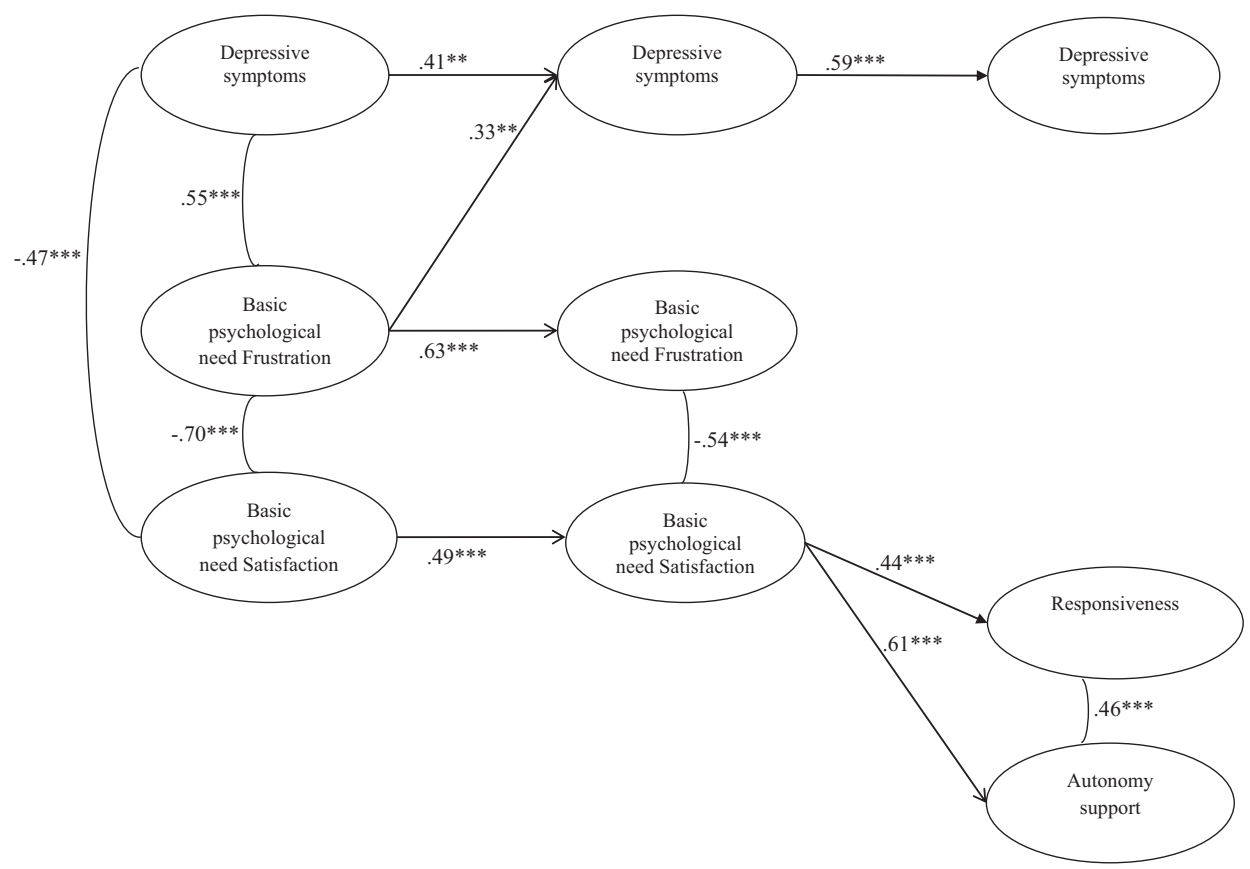

Figure 3. Integrated model. Coefficients shown are standardized path coefficients, ${ }^{*} \mathrm{p}<.05 .{ }^{* *} \mathrm{p}<.01$. $* * * \mathrm{p}<.001$.

Note. For sake of parsimony, only significant associations are presented.

In a third integrated structural model (Model 3, see Figure 3), we included both needs satisfaction and needs frustration when investigating postnatal depressive symptom and parenting quality. All significant and borderline significant associations that were found in previous structural equation models were included in this model. Estimation of this model, $\chi^{2}(433)=602,87$, $\mathrm{CFI}=.92, \mathrm{RMSEA}=.04, \mathrm{SRMR}=.09$, showed a significant effect of basic psychological needs frustration on increases in depressive symptoms across time $(\beta=.33, p<.01)$; showed that general prenatal needs satisfaction and frustration predicted more relationship-specific needs satisfaction $(\beta=.49, p<.001)$ and frustration $(\beta=.63, p<.01)$, respectively; and showed that postnatal needs satisfaction in the mother-infant relationship predicted more responsiveness $(\beta=.44, p<.001)$ and autonomy support $(\beta=.61, p<.001)$ when the child is 2 years old. The borderline significant association between postnatal depressive symptoms and maternal autonomy support when the child is 2 years old turned out nonsignificant $(\beta=-.05$, $p>.05)$.

In a final step, we tested whether the indirect paths, as modelled in Figure 3, were significant (Preacher \& Hayes, 2008). The results show a significant indirect path from Time 1 psychological needs frustration via Time 2 depressive symptoms to Time 3 depressive symptoms $(\beta=.19, p<$ .05 ), and significant paths from Time 1 psychological needs satisfaction via Time 2 relationshipspecific basic psychological needs satisfaction to both parental responsiveness $(\beta=.22, p<.01)$ and parental autonomy support $(\beta=.30, p<.001)$ as measured at Time 3 .

\section{Discussion}

To our knowledge, this study is the first to explore the longitudinal link between basic psychological needs satisfaction and frustration, postnatal depressive symptoms, and early parenting. A number of interesting findings emerged. 


\section{Women's Prenatal Basic Psychological Needs and Postnatal Depressive Symptoms}

The results indicate that prenatal needs frustration is related to more postpartum depressive symptoms, whereas the link between needs satisfaction and depressive symptoms is nonsignificant. These results are in line with the main postulates of SDT about the importance of basic psychological needs for psychological well-being (Deci \& Ryan, 2000), and with the recent study tendency to make a distinction between psychological needs satisfaction and frustration (Bartholomew et al., 2011; Vansteenkiste \& Ryan, 2013). Because prenatal needs frustration (but not needs satisfaction) is related to postnatal depressive symptoms, the results support the assumption that a lack of needs satisfaction cannot be equated to needs frustration, and that the latter involves a stronger link with ill-being.

Based on the present study's results and previous research (Brenning et al., 2015; Gauthier et al., 2010), women's feelings of failure and doubts about one's efficacy (competence needs frustration), experiences of relational exclusion and loneliness (relatedness needs frustration), and feelings of being controlled through externally enforced or self-imposed pressures (autonomy needs frustration) are assumed to be particularly relevant when investigating postnatal depressive symptoms.

However, although our results advance our understanding of the needs as potential antecedents important for postpartum depressive symptoms, a more complete understanding of predictors of postpartum depressive symptoms should also incorporate a measurement of other potential risk factors (e.g., previous psychosocial problems; Beck, 2001). Because past work examining psychological predictors of postnatal depressive symptoms has not always been grounded in an overarching psychological framework (Beck, 2001), SDT may help to explain why previously identified predictors relate to postnatal depression (Gauthier et al., 2010). For example, risk factors as outlined in the review study by Beck (e.g., self-esteem, social support, unplanned/unwanted pregnancy; see the 13 significant predictors of postpartum depression as outlined in the meta-analysis by Beck, 2001) could be linked to frustration of one or more of the basic psychological needs (i.e., frustration of competence, relatedness, autonomy, respectively). This research seems to be particularly important because previous studies (e.g., Woolhouse et al. 2016) and the current study's results show that postpartum depressive symptoms are not always transitory, but they may also predict depressive symptoms 2 to even 4 years later.

\section{Basic Psychological Needs}

The present results provide support for a link between prenatal general basic psychological needs (i.e., general level) and postnatal relationship-specific basic psychological needs (i.e., domain-specific level). These results, which could be referred to as top-down effects between two levels of needs (representations at the top of the hierarchy which influence representations lower in the hierarchy), are in line with previous research (e.g., Milyavskaya et al., 2013). For example, mothers who generally feel competent are more likely to experience feelings of competence in interaction with their child. Because previous research (Milyavskaya et al., 2013; Vallerand, 1997) makes a differentiation between three different levels of needs fulfillment (i.e., general, domain-specific and episodic level of experience), future research should also incorporate needs experiences toward a specific parental task (e.g., getting your toddler to bed).

Further, because SDT posits a heterarchical model (Berntson \& Cacioppo, 2008) expecting bottom-up (next to top-down) effects between the three different levels of needs fulfillment (i.e., representations at the lower end of the hierarchy that lead to changes in the more abstract and general representations at the top of the hierarchy; e.g., Milyavskaya et al., 2013), future research should include the measurement of general, domain-specific and episodic needs fulfillment at each measurement time. As such, further research could more thoroughly investigate the extent to which women's needs satisfaction at each level predicts general maternal well-being independently of the other levels. For example, a woman's specific episode of success in parenting (e.g., succeeding to comfort the child when he/she was upset) could serve to build up mother's 
feelings of competence in interaction with her child, which could further enhance her general feelings of competency, which could be related to women's general psychosocial well-being at each level (Deci \& Ryan, 2008; Milyavskaya \& Koestner, 2011; Patrick et al., 2007).

\section{Relationship-Specific Basic Psychological Needs as a Resource and Risk Factor for Quality of Parenting}

As a final research question, we examined whether mother's relationship-specific needs satisfaction and frustration would relate to maternal parenting quality (i.e., responsiveness and autonomy support). The results show that postnatal relationship-specific needs satisfaction related to both maternal responsiveness and autonomy support. In line with previous research (e.g., van der Kaap-Deeder et al., 2015), mothers' feelings of confidence and certainty about one's efficacy in interaction with their child (competence needs satisfaction), experiences of connection and warm interpersonal interaction with their child (relatedness needs satisfaction), and feelings of choice and freedom in interaction with their child (autonomy needs satisfaction) seem to present an important resource to provide high quality parenting. Future research should however investigate which processes (e.g., energy) are responsible for this association (e.g., Joussemet et al., 2008).

Whereas needs satisfaction was significantly related to high-quality parenting, the link between maternal needs frustration and both responsiveness and autonomy support was nonsignificant. Again, these results point to the importance of making a distinction between needs satisfaction and needs frustration. These results indeed show that needs satisfaction is particularly predictive when investigating adaptive parenting behaviors, such as responsiveness and autonomy support. Future research should also incorporate more maladaptive parenting behaviors (e.g., rejection, coercion, chaos; Zimmer-Gembeck, Webb, Thomas, \& Klag, 2015) to further disentangle this link between both needs satisfaction and frustration on the one hand and both high- and low-quality parenting behaviors on the other hand.

Finally, the results of the present research show that the link between postpartum depressive symptoms and quality of parenting was nonsignificant when incorporating basic psychological needs. Although previous research pointed to the link between postpartum depressive symptoms and quality of mother-infant interaction (e.g., Beck, 1995; Campbell et al., 2004), the current research results may indicate that relationship-specific basic psychological needs are specifically important when investigating this link. However, no firm conclusions can be drawn before these results are replicated in a large clinical sample of women with a postpartum depression.

\section{Limitations}

Although the current research provides promising results, there are some limitations that should be taken into consideration. First, the sample mostly includes women who have a partner and have a high level of education. Therefore, because the findings of the present study may not capture the experiences of mothers having a child in other life circumstances (e.g., lower socioeconomic status, single mothers), future research has to be done.

Second, the measures used in this study are all self-report scales, and all data were reported by the same source. Indeed, it is well known that self-report questionnaires create a response bias through the phenomenon of social desirability. As such, it would be preferable for future research to use more objective assessments to more accurately measure some of the constructs (e.g., observational and/or multi-informant measurement of maternal parenting quality). Third, although the study tested the prospective effects of needs satisfaction and needs frustration on postnatal depressive symptoms and early parenting, future research should be done to confirm the causality of our results. Thereby, basic psychological needs (at different levels), depressive symptoms, and parenting behaviors should be measured at each measurement wave.

Finally, one may wonder whether the significant association between general and relationshipspecific basic psychological needs represents a true predictive effect or whether it is more 
of an autoregressive effect. Previous research (e.g., La Guardia, Ryan, Couchman, \& Deci, 2000) showed that needs satisfaction and frustration may vary from one relationship to another and thus assumes that general basic psychological needs are not necessarily equivalent to relationship-specific psychological needs. However, to truly investigate whether the abovementioned association represents a true or a more autoregressive effect, further research should include measurements of both general and relationship-specific basic psychological needs at each moment in time.

\section{Conclusion}

Our results underscore the importance of needs fulfillment for women's well-being and early parenting behaviors. Given these findings, an important aim for future research is to investigate whether high-quality parenting (i.e., maternal responsiveness and autonomy support) is in turn linked to children's own psychological needs fulfillment. Previous studies already demonstrated the beneficial effects of high-quality parenting (parental autonomy support more specifically) for children's needs satisfaction (e.g., Vierling, Standage, \& Treasure, 2007) and even for intergenerational similarity in needs satisfaction (van der Kaap-Deeder et al., 2015). Ultimately, such findings may also inform (clinical) practice. Health professionals may be able to use psychological interventions that target the variables investigated in the present study when working to prevent and reduce depressive symptoms during the postpartum period and when supporting mothers to engage in high-quality interactions with their child.

\section{References}

Bartholomew, K. J., Ntoumanis, N., Ryan, R. M., Bosch, J. A., \& Thogersen-Ntoumani, C. (2011). Self-determination theory and diminished functioning: The role of interpersonal control and psychological need thwarting. Personality and Social Psychology Bulletin, 37, 1459-1473. doi: $10.1177 / 0146167211413125$

Beck, C. T. (1995). The effects of postpartum depression on maternal-infant interaction: A meta-analysis. Nursing Research, 44, 298-304.

Beck, C. T. (1996). A meta-analysis of predictors of postpartum depression. Nursing Research, 45, 297-303. doi:10.1097/00006199-199609000-00008

Beck, C. T. (2001). Predictors of postpartum depression-An update. Nursing Research, 50, $275-285$. doi:10.1097/00006199-200109000-00004

Bernier, A., Matte-Gagne, C., Belanger, M. E., \& Whipple, N. (2014). Taking stock of two decades of attachment transmission gap: Broadening the assessment of maternal behavior. Child Development, 85, 1852-1865. doi:10.1111/cdev.12236

Berntson, G. G., \& Cacioppo, J. T. (2008). The neuroevolution of motivation. In J. Y. Shah \& W. L. Gardner (Eds.), Handbook of motivation science (pp. 188-200). New York: Guilford Press.

Bindman, S. W., Pomerantz, E. M., \& Roisman, G. I. (2015). Do children's executive functions account for associations between early autonomy-supportive parenting and achievement through high school? Journal of Educational Psychology, 107, 756-770. doi:10.1037/edu0000017

Bouma, J., Ranchor, A. V., Sanderman, R., \& van Sonderen, E. (1995). Measuring depressive symptoms using the CES-D: A manual. University of Groningen. Netherlands.

Bowlby, J. (1980). Attachment and loss: Vol 3. Sadness and depression. New York: Basic Books.

Brenning, K., Soenens, B., Braet, C., \& Bal, S. (2012). The role of parenting and mother-adolescent attachment in the intergenerational similarity of internalizing symptoms. Journal of Youth and Adolescence, 41, 802-816. doi:10.1007/s10964-011-9740-9

Brenning, K., Soenens, B., Mabbe, E., \& Vansteenkiste, M. (2017). Ups and Downs in the Joy of Parenthood: A Diary Study Examining Variability in Maternal Well-being as a Function of Basic Psychological Needs, Parent Personality, and Infant Temperament. (In press).

Brenning, K., Soenens, B., \& Vansteenkiste, M. (2015). What's your motivation to be pregnant? examining relations between pregnant women's motives for having a child and their prenatal functioning. Journal of Family Psychology, 29, 755-765. 
Campbell, S. B., Brownell, C. A., Hungerford, A., Spieker, S. J., Mohan, R., \& Blessing, J. S. (2004). The course of maternal depressive symptoms and maternal sensitivity as predictors of attachment security at 36 months. Development and Psychopathology, 16, 231-252. doi:10.1017/s0954579404044499

Chen, B., Vansteenkiste, M., Beyers, W., Boone, L., Deci, E. L., Duriez, B., . . Verstuyf, J. (2015). Basic psychological need satisfaction, need frustration, and need strength across four cultures. Motivation and Emotion, 39, 216-236. doi:DOI 10.1007/s11031-014-9450-1

Cowan, C., \& Cowan, P. (2000). When Partners become parents: The big life change for couples. Mahway NJ: Erlbaum Associates.

Davidov, M., \& Grusec, J. E. (2006). Untangling the links of parental responsiveness to distress and warmth to child outcomes. Child Development, 77, 44-58. doi:10.1111/j.1467-8624.2006.00855.x

Deci, E. L., \& Ryan, R. M. (2000). The "what" and "why" of goal pursuits: Human needs and the selfdetermination of behavior. Psychological Inquiry, 11, 227-268. doi:10.1207/s15327965pli1104_01

Deci, E. L., \& Ryan, R. M. (2008). Facilitating optimal motivation and psychological well-being across life's domains. Canadian Psychology-Psychologie Canadienne, 49, 14-23. doi:10.1037/07085591.49.1.14

Gauthier, L., Guay, F., Senecal, C., \& Pierce, T. (2010). Women's depressive symptoms during the transition to motherhood the role of competence, relatedness, and autonomy. Journal of Health Psychology, 15, 1145-1156. doi:10.1177/1359105310364170

Gavin, N. I., Gaynes, B. N., Lohr, K. N., Meltzer-Brody, S., Gartlehner, G., \& Swinson, T. (2005). Perinatal depression-A systematic review of prevalence and incidence. Obstetrics and Gynecology, 106, 10711083. doi:10.1097/01.AOG.0000183597.31630.db

Goodman, J. H. (2004). Postpartum depression beyond the early postpartum period. Jognn-Journal of Obstetric Gynecologic and Neonatal Nursing, 33, 410-420. doi:10.1177/0884217504266915

Grolnick, W. S., Deci, E. L., \& Ryan, R. M. (1997). Internalization within the family: The self-determination theory perspective. In J. E. Grusec \& L. Kuczynski (Eds.), Parenting and childrens' internalization of values: A handbook of contemporary theory (pp. 78-99). London: Wiley.

Grolnick, W. S., Ryan, R. M., \& Deci, E. L. (1991). Inner resources for school-achievement: Motivational mediators of children's perceptions of their parents. Journal of Educational Psychology, 83, 508-517. doi:10.1037/0022-0663.83.4.508

Joussemet, M., Landry, R., \& Koestner, R. (2008). A self-determination theory perspective on parenting. canadian Psychology-Psychologie Canadienne, 49, 194-200. doi:10.1037/a0012754

Kline, R. B. (2010). Principles and practice of structural equation modeling (3rd ed.). New York: Guilford Press.

Kochanska, G., Aksan, N., Knaack, A., \& Rhines, H. M. (2004). Maternal parenting and children's conscience: Early security as moderator. Child Development, 75, 1229-1242. doi:10.1111/j.14678624.2004.00735.x

Kochanska, G., Murray, K. T., \& Harlan, E. T. (2000). Effortful control in early childhood: Continuity and change, antecedents, and implications for social development. Developmental Psychology, 36, 220-232. doi:10.1037//0012-1649.36.2.220

La Guardia, J. G., Ryan, R. M., Couchman, C. E., \& Deci, E. L. (2000). Within-person variation in security of attachment: A self-determination theory perspective on attachment, need fulfillment, and well-being. Journal of Personality and Social Psychology, 79, 367-384. doi:10.1037//0022-3514.79.3.367

Little, R. J. A., \& Rubin, D. B. (1987). Statistical analysis with missing data. New York: Wiley.

Mabbe, E., Soenens, B., Vansteenkiste, M., van der Kaap-Deeder, J., \& Mouratidis, A. (in press). Day-to-day variation in autonomy-supportive and psychologically controlling parenting: The role of parents' daily experiences of need satisfaction and need frustration. Parenting-Science and Practice.

Miller, L. J. (2002). Postpartum depression. Jama-Journal of the American Medical Association, 287, 762 765. doi:10.1001/jama.287.6.762

Milyavskaya, M., \& Koestner, R. (2011). Psychological needs, motivation, and well-being: A test of selfdetermination theory across multiple domains. Personality and Individual Differences, 50, 387-391. doi:10.1016/j.paid.2010.10.029

Milyavskaya, M., Philippe, F. L., \& Koestner, R. (2013). Psychological need satisfaction across levels of experience: Their organization and contribution to general well-being. Journal of Research in Personality, 47, 41-51. doi:10.1016/j.jrp.2012.10.013

Muthén, L. K., \& Muthén, B. O. (2012). Mplus user's guide (Vol. 7). Los Angeles: CA: Muthén \& Muthén. 
Patrick, H., Knee, C. R., Canevello, A., \& Lonsbary, C. (2007). The role of need fulfillment in relationship functioning and well-being: A self-determination theory perspective. Journal of Personality and Social Psychology, 92, 434-457. doi:10.1037/0022-3514.92.3.434

Preacher, K. J., \& Hayes, A. F. (2008). Asymptotic and resampling methods for estimating and comparing indirect effects. Behavior Research Methods, 40, 879-891.

Radloff, S. L. (1977). The CES-D scale: A self-report depression scale for research in the general population. Applied Psychological Measurement, 1, 385-401.

Roberts, R. E., \& Sobhan, M. (1992). Symptoms of depression in adolescence: A comparison of Anglo, African, and Hispanic americans. Journal of Youth and Adolescence, 21, 639-651. doi:10.1007/bf01538736

Ryan, R., Deci, E., \& Vansteenkiste, M. (2016). Autonomy and autonomy disturbances in self-development and psychopathology: Research on motivation, attachment, and clinical process. In D. Cicchetti (Ed.), Developmental psychopathology (3rd ed., Vol. 1, pp. 385-438). New York: Wiley.

Ryan, R. M., \& Deci, E. L. (2000). Self-determination theory and the facilitation of intrinsic motivation, social development, and well-being. American Psychologist, 55, 68-78. doi:10.1037//0003066x.55.1.68

Ryan, R. M., Deci, E. L., Grolnick, W. S., \& La Guardia, J. G. (2006). The significance of autonomy and autonomy support in psychological development and psychopathology. In D. Cicchetti \& D. Cohen (Eds.), Developmental psychopathology: Vol. 1. Theory and methods. New York: Wiley.

Ryan, R. M., \& Frederick, C. (1997). On energy, personality, and health: Subjective vitality as a dynamic reflection of well-being. Journal of Personality, 65, 529-565. doi:10.1111/j.1467-6494.1997.tb00326.x

Schaefer, E. S. (1965). Children's reports of parental behavior: An inventory. Child Development, 36, 413-424.

Soenens, B., Duriez, B., Vansteenkiste, M., \& Goossens, L. (2007). The intergenerational transmission of empathy-related responding in adolescence: The role of maternal support. Personality and Social Psychology Bulletin, 33, 299-311. doi:10.1177/0146167206296300

Soenens, B., Luyckx, K., Vansteenkiste, M., Duriez, B., \& Goossens, L. (2008). Clarifying the link between perceived parental psychological control and adolescents' depressive feelings: Reciprocal versus unidirectional models of influence. Merrill-Palmer Quarterly, 54, 411-444.

Soenens, B., Vansteenkiste, M., Lens, W., Luyckx, K., Goossens, L., Beyers, W., \& Ryan, R. M. (2007). Conceptualizing parental autonomy support: Adolescent perceptions of promotion of independence versus promotion of volitional functioning. Developmental Psychology, 43, 633-646. doi:10.1037/00121649.43.3.633

Soenens, B., Vansteenkiste, M., Luyckx, K., \& Goossens, L. (2006). Parenting and adolescent problem behavior: An integrated model with adolescent self-disclosure and perceived parental knowledge as intervening variables. Developmental Psychology, 42, 305-318. doi:10.1073/0012-1649.42.2.305

Vallerand, R. J. (1997). Toward a hierarchical model of intrinsic and extrinsic motivation. In M. P. Zanna (Ed.), Advances in experimental social psychology (Vol. 29, pp. 271-360). San Diego: Academic Press.

van der Kaap-Deeder, J., Vansteenkiste, M., Soenens, B., Loeys, T., Mabbe, E., \& Gargurevich, R. (2015). Autonomy-supportive parenting and autonomy-supportive sibling interactions: The role of mothers' and siblings' psychological need satisfaction. Personality and Social Psychology Bulletin, 41, 1590-1604. doi:10.1177/0146167215602225

Vansteenkiste, M., Niemiec, C. P., \& Soenens, B. (2010). The five mini-theories of self-determination theory: An historical overview, emerging trends, and future directions. In T. C. Urdan \& S. A. Karabenick (Eds.), Advances in motivation and achievement: Vol. 16A. The decade ahead: Theoretical perspectives on motivation and achievement (1st ed., pp. 105-166). Bingley,UK: Emerald.

Vansteenkiste, M., \& Ryan, R. M. (2013). On psychological growth and vulnerability: Basic psychological need satisfaction and need frustration as a unifying principle. Journal of Psychotherapy Integration, 23, 263-280. doi:10.1037/a0032359

Verhoeven, M., Junger, M., Van Aken, C., Dekovic, M., \& Van Aken, M. A. G. (2007). Parenting during toddlerhood-Contributions of parental, contextual, and child characteristics. Journal of Family Issues, 28, 1663-1691. doi:10.1177/0192513x07302098

Vierling, K. K., Standage, M., \& Treasure, D. C. (2007). Predicting attitudes and physical activity in an "at-risk" minority youth sample: A test of self-determination, theory. Psychology of Sport and Exercise, 8, 795-817. doi:10.1016/j.psychsport.2006.12.006 
Whipple, N., Bernier, A., \& Mageau, G. A. (2011). Broadening the study of infant security of attachment: Maternal autonomy-support in the context of infant exploration. Social Development, 20, 17-32. doi:10.1111/j.1467-9507.2010.00574.x

Woolhouse, H., Gartland, D., Mensah, F., Giallo, R., \& Brown, S. (2016). Maternal depression from pregnancy to 4 years postpartum and emotional/behavioural difficulties in children: Results from a prospective pregnancy cohort study. Archives of Womens Mental Health, 19, 141-151. doi:10.1007/s00737-0150562-8

Zimmer-Gembeck, M. J., Webb, H. J., Thomas, R., \& Klag, S. (2015). A new measure of toddler parenting practices and associations with attachment and mothers' sensitivity, competence, and enjoyment of parenting. Early Child Development and Care, 185, 1422-1436. doi:10.1080/03004430.2014.1001753

All procedures performed involving human participants in this study were in accordance with the ethical standards of Ghent University University's Institutional Review Board and with the 1964 Helsinki declaration and its later amendments or comparable ethical standards. 